\title{
The Design, Development, And Evaluation Of Database Projects In Accounting Classes
}

\author{
Mark G. Simkin, (E-mail: simkin@unr.edu), University of Nevada, Reno
}

\begin{abstract}
This paper describes a comprehensive database term project and several ideas that instructors can use to facilitate good projects and streamline the grading process. The author tested the effectiveness of this assignment with an end-of-semester student survey, a comparison of groupversus-individual project performance, and an examination of his end-of-semester course evaluations. His analyses suggest that term projects are an effective way to help students learn database concepts, and therefore should be included among the "best practices" associated with teaching database subjects.
\end{abstract}

\section{INTRODUCTION}

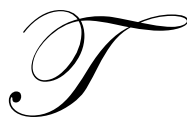

he importance of technology in accounting practice is well-documented, as is the importance of using and teaching "technology concepts" in accounting classes (Burnett, 2003; Howieson, 2003; Kalbers and Rosner, 2003; Lont, et. al, 1998; Goldsworthy, 1996). Less clear is how best to perform such teaching tasks, or how best to evaluate student work in technology-related assignments (Van Meer and Adams, 1996; Quarstein and Peterson, 2001).

Database concepts were one of the nine broad topics recommended by an early AAA study (1987) for the core AIS curriculum, and are of special interest to the author. One reason for this interest stems from the importance of databases to almost all accounting information systems. Another reason is the fact that accountants can no longer be passive observers in the design and definition of accounting databases, but must now fully understand such topics as data modeling, database development, and database usage (Bowen, et. al., 2003; McCarthy, 2003). Yet a third reason is the growing awareness among accounting teachers that those students possessing deeper understanding of database development and usage are more desirable to employers than those without such skills (Howieson, 2003; Burnett, 2003, Van Meer and Adams, 1996). Finally, as a teacher himself, the author recognizes that "teaching database skills effectively" is an integral part of the typical university accounting curriculum as well as a professional mandate.

The question of how best to teach database concepts has not received consistent answers in the literature. At one time, the simple ability to define a few data fields and relational tables seemed sufficient to fulfill this obligation. For the reasons cited above, those days are gone. They have been replaced with the need to teach a much broader set of concepts, including normalization, REA, query construction, output design concerns, and even macro programming (McCarthy, 2003; IMA, 2000).

This paper examines these needs within the context of the accounting curriculum, and focuses on the use of term projects to equip students with the database skills required of the profession. The next section of this paper examines these skill requirements in detail and discusses the potential for term projects to perform this job. The third section of the paper describes such a project in detail and discusses the relevant components. The fourth section of this paper reports the results of a survey that evaluated student perceptions of the value of such projects. The final section of this paper provides a summary and conclusions. 


\section{ADVANTAGES AND CONCERNS OF DATABASE TERM PROJECTS}

A number of teachers believe that term projects enjoy special advantages over many other types of homework assignments (Bradley and Monk, 2003; Graham and Graham, 1997). One of the most important is the ability to assign a comprehensive task that more closely reflects the unstructured problems characteristic of the modern workplace (Bryant, 2001). A concomitant expectation is that term projects challenge students to synthesize what they have learned at different times and in different ways in a given course, and therefore better prepare students to solve challenging problems with these tools (Bhattacharjee and Shaw, 2001). Certainly, learning database concepts would appear to fit these expectations, inasmuch as modern databases are usually complex structures whose concepts and techniques must necessarily be taught piecemeal during the course of a semester.

A second set of advantages involves the benefits of student work outside the classroom. Bhattacharjee and Shaw (2001) note, for example, that term projects enable students to meet with colleagues and friends in comfortable venues, utilize a wide range of sources to help them overcome obstacles to the successful completion of their tasks, and perhaps gain skills that were difficult for them to understand or were not taught in the classroom.

Many scholars also assign term projects in order to encourage original thinking from students and foster creativity. When students must design and develop their own applications and there is no one right answer, there is the additional hope that such assignments limit the amount of copying that students can do outside of class on the same assignment. In the matter of term papers and the large number of "term-paper-helper" resources now available on the web, such expectations have often been thwarted (Schrage, 2000). However, the author is not aware of similar problems for database applications.

A fourth set of benefits potentially accrues to those instructors who assign project work to teams of student rather than individuals. Bryant (2001), for example, suggests that such assignments help develop critical thinking, team building, and communication skills. Another advantage is the likelihood that the more competent members of student teams will augment the skills of their weaker colleagues, and in the process, teach them subject material that they did not first understand (Graham and Graham, 1997). There is also the hope that such projects will raise overall class understanding of important concepts and boost overall student confidence, pride of accomplishment, and positive feelings of ownership about the final outputs.

Lastly, it is important to note the positive effect that team projects can have on student perceptions of overall course quality. The literature on collaborative learning consistently emphasizes the claim that team projects enhance student morale, and positive perceptions of instructor performance (Berry and Nyman, 2002). These are no small advantages. In a study using focus groups, the IMA (2000) found that "the most critical element in a student's classroom experience was an inspiring professor." Other researchers provide anecdotal evidence indicating positive feedback as well as improvements in their student course evaluations (Hite, 1996). There is consequently good reason to believe that such advantages will apply to a database term project.

Term project assignments are not unconditionally embraced by all accounting faculty. One concern is the fact that assigning term projects comes at the cost of time needed to assign, discuss, explain, possibly debug, and grade them. Such efforts therefore require faculty to weigh the benefits of such assignments against the costs. These considerations are especially important to the faculty at research-oriented schools, which tend to stress, and mostly reward, publication productivity, and either marginally count teaching creativity or ignore it entirely.

Another concern is the fact that evaluating term projects typically requires the professional judgment of the instructor. To the extent that such assessments are also subjective, the grading process exposes faculty to potential confrontations with students about their final project grades, can reduce positive feedback on student evaluations, and is therefore a concern in our litigious society. 


\section{DESIGNING, DEVELOPING, AND GRADING A DATABASE PROJECT}

The idea that term projects better help students understand database concepts is itself a testable hypothesis. The starting point for the author was the task of teaching advanced microcomputer subjects to a class of undergraduate business students at a 15,000-student, land-grant western university. Although initially designed as a "transition course" for potential information systems majors, the author was surprised to find that the majority of the students in these classes each semester were not information systems majors - and that many of them were accounting students. Subsequent analysis also revealed that the two most important applications in this class were spreadsheets and databases. Thus, over time, such other topics as advanced Windows skills, detailed presentation software skills, and hardware matters were dropped from the course in order to devote more time to these primary skill sets.

With our new focus, it remained to determine how best to teach these two applications. One decision was to standardize our software adoptions on Microsoft Access and Excel. But the idea of using a term project for the Access portion of the class did not begin with the creation of the course. Rather, the project and its requirements evolved slowly over several semesters as it became clear that student understanding of database concepts seemed fragmented without an integrative case, and that a comprehensive project might help them "put the pieces together." Thus the instructors teaching the various sections of the course agreed to include a common database project in their assignment sets, and to experiment with the parameters guiding its design and development.

\section{Project Components}

At the initiation of the project, we were using a textbook by Hutchinson and Coulthhard (2000), and had little guidance about what to assign in these projects. However, it certainly made sense to require students to demonstrate many of the database skills taught in that book-for example, creating data fields organized into tables, relationships, various types of simple and advanced select and action queries, input forms, and a set of reports based upon these tables and queries. We also began requiring students to use some of the advanced features of Access as these became available, including primary and secondary switchboards, relationships documentation, hyperlinks, mail merge applications, graphs, pivot charts, macros, and (simplified) VBA code.

Figure 1 provides a complete requirements list for the current Access project—a list that has evolved over five or more semesters along with our ideas about what we should be teaching. We give students a copy of these requirements (along with an expanded description of the project) at the beginning of the semester, which students can then use as a set of skills that they must learn in order to meet the project requirements as well as a "punch list" of deliverables for the project itself. In practice, we also find that the list often acts as motivation tool that leads to questions germane to both the general topic for the class day as well as the specific project of the questioners.

When we switched from the Hutchinson and Coulthard text to the Graurer and Barber (2002) book, we found an outline of a possible project assignment that those authors use at the University of Miami. Although the exact requirements of Figure 1 do not precisely conform to the ones outlined on pages 446-7 of that book, they are remarkably similar and therefore lent credibility to the work that we had been assigning without the benefit of this outline. Over the course of four or five semesters and three versions of the software, we have revised our project requirements to include new tools as well as to refine our weighting scheme.

The overall objectives of our project match those of Graurer and Barber-to create a small database application that includes the components outlined in Figure 1. In both instances, students are free to choose an application of interest to them, and we encourage our students to choose applications of personal value. Examples include database systems that track collections such as stamps, baseball cards, dolls, or music CDs, name-andaddress lists, weddings, recipes, customer lists for a family-owned boat-storage business, and in one notable project ghost sightings. 


\section{Designing Normalized Tables}

There are many reasons why it is important for database designers to create normalized tables (see, for example, Bowen and Rohde, 2002). Perhaps the most challenging portion of the term project was the requirement that each project database contain at least four tables, at least two of which have a many-to-many relationship. This, in turn, required students to grapple with the construction of a third "details" table in Access. Although some students understood these concepts intuitively, others struggled with them-for example, because they did not understand them or because they did not understand how their particular application could possibly contain so many tables or such a complex relationship.

Our experience was that this was a major problem. One cause was the fact that the students taking our class had only completed one, freshman-level computer fundamentals course as a prerequisite, and therefore had no prior data modeling or database design experience. Another reason was because many of the remaining project requirements depend upon well-defined tables as an underlying foundation. Finally, we found that those students who lacked well-designed tables had often performed a good deal of subsequent (flawed) work before realizing they needed help. The result was that the revisions we recommended required students to either abandon such work, or to modify their database components to the point where starting from scratch would make more sense.

The solution to this problem was to require students to create their project's deliverables in phases, just as they would in a real application. Although we adopted this idea independently, our requirement closely follows the suggestion by Grauer and Barber (2002) that the term project proceed in phases, including Phase I (Preliminary design) and Phase II (Detailed Design). Thus, after covering the beginning material on developing and designing database fields and tables at the start of the semester, we now require students to write a preliminary report describing their application. This report includes a list of potential tables and a list of fields for each table. We do not grade this report, but use it to identify faulty table designs, which we then require students to revise before allowing them to proceed further with their projects.

\section{Project Deliverables}

At the project's due date, students are required to provide their instructor with a complete, working version of their software on a (floppy or CD) disk as well as a complete set of documentation. Documentation items include (1) a report that explains the motivation for their project and instructions on how to use their applications, and (2) documentation for such ancillary enhancements as a mail merge with Microsoft word.

Although it may not be obvious from Figure 1, we also ask for several additional project deliverables. One requirement is that students present their database application to the entire class in a short oral presentation of five minutes or less. This does not give students very much time in which to cover the various details of their work, but is a practical limitation imposed by the number of students typically enrolled in any one section of this class-e.g., 25 to 30 individuals. One reason for this presentation requirement was simply to allow students to "brag" about their work. A more important reason was to expose the other students in the class to the many possible applications of databases beyond those found in the textbook. Because many of our students work part-time off campus and base their term projects on their work experience, another rationale was to allow such students to demonstrate applications of databases in real, industrial settings.

In order to present their work in class, students must use the existing hardware of the classroom and come prepared to walk through their entire projects in a remarkably short period of time. Thus, some final reasons for the oral-report requirement of this project was to force students to carefully organize their presentations, give them experience in preparing technical talks that depended upon the proper functioning of compatible hardware, and of course practice good oral communication skills.

When we first began assigning these term projects, we required students to present their work on the same day that the assignment was due. Our thinking was that all students would have completed their work by this date, and thus would be ready to present their projects to others. As we gained experience with this assignment, however, 
we found several reasons why we should delay the actual turn-in date until after these presentations were given. One reason for this change in thinking was because we noticed that presenters often demonstrated tools or techniques that at least some of the other students had forgotten to include, or presented exciting enhancements that could be replicated in other projects. Another reason was because the presentations helped students recognize the importance of graphics, color, and similar visual elements in their database designs - components that were often overlooked in the rush to satisfy the other design requirements of the assignment. Thus, we would typically receive numerous requests for more time to make revisions. We thought that the fairest way to handle these requests was a policy that set the due date for the projects in the class period following the presentation day(s).

\section{Grading}

The author estimates that it takes him between 10 and 20 minutes to grade the average Access project as described here. But he notes that a substantial amount of additional classroom and office-hour time can be spent answering student questions, consulting with individuals, trouble-shooting problems, and so forth. For the reasons cited above, the author believes that the benefits that accrue to assigning these term projects outweigh their costs. He also believes that there are several things that faculty can do to streamline the grading process as well as reduce the amount of time spent grading. One of the most useful of these is to adopt a standardized grading sheet similar to the one in Figure 1. Although students mostly view this sheet as a large list of project requirements, it also helps standardize the evaluation process and provides objective evidence of fair and impartial assessments.

We have also been able to streamline the grading process by providing space on the form (not shown in Figure 1) for students to indicate exactly where each of the components can be found in their projects. Although this option provides guidance for the instructor, we find that requiring such information forces students to carefully evaluate their own projects and become better aware of what's missing from them.

As a general rule, the author has also found that good term projects are easy to grade whereas deficient ones or ones that have been rushed to completion take more time. Thus, another way to make these database projects easier to grade is to ensure higher levels of competence in their development. Towards this end, one of the instructors of this class is now experimenting with a "pre-grading" exercise which takes place a week or two prior to the actual due date of the project. In this experiment, students provide a working model of their database to a blind (student) referee, who then evaluates it using the criteria in Figure 1. Students receive their "grades" within a week, which they can they use to revise their projects based upon this feedback.

Yet a third way that instructors can reduce grading efforts is to require students to work in teams-for example, of three students each. In a class of size 30, this reduces the required number of projects to grade from 30 to 10 . As noted above, there are many reasons why instructors might require students to work in groups other than this consideration, but the grading advantage of such a requirement is substantial.

Finally, instructors might consider the possibility of allowing students to grade each other's work entirely. Although this possibility might seem extreme, the author has experimented with it in other classes with surprisingly successful results (Marcoulides and Simkin, 1991). Where students work in groups, such efforts encourage graders to discuss the extent to which the assignment's developers did or did not create particular project components and what penalties are fair for non-conformance. In addition, the author has found that this collaborative work empowers students as reviewers and is a cornerstone of the peer-review process they will experience later as accounting professionals.

\section{Adjustments to Term Project Scores}

Over time, we have found it useful to make provision for several adjustments to term project grades, as shown in the lower portion of the grading sheet in Figure 1. One item is a small (five percent) penalty for class absence during presentation days. One rationale for this penalty is to make sure that students are able to present their work to a "full house" of attendees. Also, for the reasons cited above, we feel that our student reports are good learning experiences for the others. We find that the small (five percent) penalty we now impose for missing class 
on those days is sufficient to motivate most students to attend.

As noted above, classroom demonstrations take time and we want to make sure that students "load-go" when their turn comes to present. Accordingly, we also impose a small (five percent) penalty for wasting class time setting up disks, launching projects, and so forth. Because students can come to class early on any day to practice loading their projects on the classroom computer, we feel this is fair. In practice, the author has never had to impose such a penalty - the mere potential for one seems sufficient to ensure that preparations go smoothly. A similar statement applies to the possibility of viral infections - the author has never had to impose this penalty - but the stiff "fine" for a virus infection makes clear what we think of this problem.

Finally, we have noticed that motivated students are very creative, and often wish to add additional enhancements to their projects. We, as instructors, like to encourage and award students for such work, and therefore include a "cushion" of up to five bonus points for such work. The author has made several such awards, and has noticed that they allow some students to catch up on missing components in some cases, earn bonuses in other cases, and create good will in all cases.

\section{EVALUATING THE EFFECTIVENESS OF PROJECT ASSIGNMENTS}

The claim that term projects are a good idea is itself a testable hypothesis. The difficulty lies in identifying an effective method to perform such a test. Quarstein and Peterson note that "the literature is replete with ways to evaluate traditional classroom instruction... [but] these evaluative methods do not readily apply to nontraditional approaches such as case study courses...or courses in which group learning is enhanced in various ways" (Quarstein and Peterson, 2001, p. 60).

To the author, the best measure of the effectiveness of the term projects discussed here would be objective evidence that such assignments significantly enhance student learning. (Here, the term "significant" means "statistically significant"-i.e., unlikely to be attributable to chance.) Perhaps the best way to show this would be to perform a classic "treatment experiment" in which the students in one or more classes would be required to complete a term project while the students in one or more "control classes" would not. Comparative performance on a common examination would perform the desired test of learning effectiveness of the two groups.

But the idea that student performance on a common final exam would be a good surrogate measure of student understanding, and therefore serve as a basis for such an evaluation, has serious problems. For example, the classes would not be the same, the students would not be the same, and the exact amount of material covered or taught would be unequal (unless presented by the same instructor who presented lecture materials and answered the same questions from students in exactly the same way). Moreover, in the opinion of the author, "withholding" the project assignment from one or more "control" classes raises serious ethical concerns, not least of which would be the unequal treatment of students in different sections of the same class.

\section{A Survey}

If it is impossible, impractical, or unethical to evaluate the desirability of the database project in the ideal manner described above, it was at least possible to canvass student opinion to determine if students perceived some benefits from it (Graham and Graham, 1997). Accordingly, the author performed a survey of all the students taking the class in the fall semester of 2003. The appendix of this paper contains a copy of the survey instrument.

The ten questions of this survey used a five-point Likert scale to gather student opinions regarding the usefulness of the project assignment to help them understand the various database concepts taught in the course itself. The scale used scores of 1 for "strongly agree," 2 for "agree," 3 for "neutral," 4 for "disagree," and 5 for "strongly disagree" as shown in the instrument. There was no place on the survey to indicate "not sure," but it is doubtful that the absence of such an answer was a problem. This is because almost all students were positive about the project and therefore would probably not have used such a category. 
Minimum Components

\begin{tabular}{|c|c|}
\hline $\begin{array}{l}\text { Tables } \\
\text { minimum })\end{array}$ & $\begin{array}{l}\text { Project should include at least four tables with a minimum of } 20 \text { re } \\
\text { throughout the database }\end{array}$ \\
\hline & Four tables, each with at least five data fields \\
\hline & At least one required field per table \\
\hline & At least one "one-to-many" relationship between two tables \\
\hline & At least one "many-to-many" relationship between two tables \\
\hline & At least one lookup field \\
\hline & At least one validation test (with validation rule) per table \\
\hline & At least one input mask \\
\hline & $\begin{array}{l}\text { At least two fields that are not text, number, or lookup fields } \\
\text { Well formatted and documented relationships report }\end{array}$ \\
\hline
\end{tabular}

\begin{tabular}{c|c} 
Forms & These are for data entry by the end user. They should be colorful, well-
\end{tabular} \begin{tabular}{l|l} 
(2 minimum) & formatted, and easy to use.
\end{tabular}

Two forms, formatted, easy to use

Logial flow of tab order in all forms

Good formatting of all labels and text fields

Custom design, color, and logos

One option button group

At least four command buttons

\begin{tabular}{|l|l|}
\hline $\begin{array}{l}\text { Queries } \\
\text { minimum })\end{array}$ & These should present useful information to the end user. At least one should \\
\hline
\end{tabular}
be a parameter query.

Three queries

One query contains a computed field

One parameter query

One select query that includes criteria

One multitable query

One query that computes sums or similar computations

One action or cross tabs query

\begin{tabular}{|c|c|}
\hline $\begin{array}{c}\text { Reports } \\
\text { (3 minimum) }\end{array}$ & These formatted outputs provide useful information to the user. \\
\hline & $\begin{array}{c}\text { Three reports that provide useful information } \\
\text { One report based on query } \\
\text { One bound graphic chart (e.g., a bar chart) } \\
\text { One report that includes sums, averages, etc. } \\
\text { Proper formatting for both heading lines and data values }\end{array}$ \\
\hline $\begin{array}{c}\text { Macros } \\
\text { (4 minimum) }\end{array}$ & $\begin{array}{l}\text { Four macros are required at a minimum. One should be an autoexec macro } \\
\text { and one should be an exit macro. }\end{array}$ \\
\hline & $\begin{array}{c}\text { Four different types of macros } \\
\text { Autoexec macro } \\
\text { One macro group } \\
\end{array}$ \\
\hline Switchboards & Should be colorful and include clipart. \\
\hline & $\begin{array}{l}\text { Main switchboard (with Exit option and links to other switchboards) } \\
\text { Good use of color and clip art } \\
\text { Three secondary switchboards, including one for reports and one for forms }\end{array}$ \\
\hline $\begin{array}{c}\text { Additional } \\
\text { Components }\end{array}$ & These additional items are required in this project. \\
\hline
\end{tabular}

Clear written explanation (in a hard copy word document) of your application, your motivation for creating it, a description of its components, and clear instructions how to use it.

Used proper naming conventions

Linked Mail Merge application or similar component

Hyperlink to your email address(es)

One imported or exported Excel spreadsheet

One pivot table and chart

Presentation (5 minutes or less!)

Subtotal:

Missed class during presentations

Wasted class time preparing for presentation

Virus Infection

Extra enhancement used as a "makeup" for a missing component (must be documented)

Final Score:

\begin{tabular}{|c|c|}
\hline Points & Score \\
\hline 25 & \\
\hline 8 & \\
\hline 2 & \\
\hline 2 & \\
\hline 2 & \\
\hline 2 & \\
\hline 4 & \\
\hline 1 & \\
\hline 2 & \\
\hline 2 & \\
\hline 10 & \\
\hline 2 & \\
\hline 1 & \\
\hline 2 & \\
\hline 2 & \\
\hline 1 & \\
\hline 2 & \\
\hline 9 & \\
\hline 3 & \\
\hline 1 & \\
\hline 1 & \\
\hline 1 & \\
\hline 1 & \\
\hline 1 & \\
\hline 1 & \\
\hline 16 & \\
\hline 6 & \\
\hline 2 & \\
\hline 2 & \\
\hline 2 & \\
\hline 4 & \\
\hline 7 & \\
\hline 4 & \\
\hline 1 & \\
\hline 2 & \\
\hline 10 & \\
\hline 2 & \\
\hline 2 & \\
\hline 6 & \\
\hline 23 & \\
\hline 10 & \\
\hline 1 & \\
\hline 2 & \\
\hline 1 & \\
\hline 2 & \\
\hline 2 & \\
\hline 5 & \\
\hline 100 & \\
\hline$(-5)$ & \\
\hline$(-5)$ & \\
\hline$(-20)$ & \\
\hline (up to 5) & \\
\hline
\end{tabular}


Figure 2 provides some selected results. The first column of this figure lists the question number and a mnemonic for it. For example, Question 1 (with mnemonic "Tables") stated "The project helped me understand the importance of Access tables," Question 2 stated "The project helped me understand the importance of Access queries," and so forth. Columns 2-6 of this figure show the number of responses for questions 1-10 of the survey instrument. Thus, for example, 29 students strongly agreed with the statement in question 1, 11 students agreed with the statement, and so forth. The exact number of responses to each question is shown in column 7 of the table. Not every student answered every question, so these numbers differ slightly from question to question - a typical result in surveys of this sort.

Figure 2: Frequency distributions and other statistics for the responses to the survey instrument in Figure 1

\begin{tabular}{|l|c|c|c|c|c|c|c|c|}
\hline Question & $\begin{array}{c}1 \\
\text { (Strongly } \\
\text { Agree) }\end{array}$ & $\begin{array}{c}2 \\
\text { (Agree) }\end{array}$ & $\begin{array}{c}3 \\
\text { (Neutral) }\end{array}$ & $\begin{array}{c}4 \\
\text { (Disagree) }\end{array}$ & $\begin{array}{c}5 \\
\text { (Strongly } \\
\text { Disagree) }\end{array}$ & $\begin{array}{c}\text { Number of } \\
\text { Responses }\end{array}$ & $\begin{array}{c}\text { Percent in } \\
\text { categories } \\
1 \text { and 2 }\end{array}$ & $\begin{array}{c}\chi^{2}=\text { Chi- } \\
\text { Square Test } \\
\text { Statistic* }\end{array}$ \\
\hline 1: Tables & 29 & 11 & 2 & 3 & 1 & 46 & $87 \%$ & 60.09 \\
\hline 2: Queries & 22 & 14 & 6 & 3 & 1 & 46 & $78 \%$ & 32.91 \\
\hline 3: Forms & 28 & 11 & 2 & 5 & 0 & 46 & $85 \%$ & 55.52 \\
\hline 4: Reports & 26 & 10 & 6 & 4 & 0 & 46 & $78 \%$ & 44.00 \\
\hline 5: Switchboards & 33 & 8 & 1 & 1 & 3 & 46 & $89 \%$ & 80.52 \\
\hline 6: Macros & 31 & 10 & 1 & 2 & 2 & 46 & $89 \%$ & 70.30 \\
\hline 7: Presentations & 13 & 11 & 11 & 3 & 7 & 45 & $53 \%$ & 7.11 \\
\hline 8: Grade Sheet & 35 & 5 & 1 & 0 & 4 & 45 & $89 \%$ & 95.78 \\
\hline 9: Fit Together & 28 & 11 & 2 & 4 & 1 & 46 & $85 \%$ & 54.65 \\
\hline 10: Weighting & 16 & 16 & 8 & 4 & 1 & 45 & $71 \%$ & 20.89 \\
\hline
\end{tabular}

* All values statistically significant at .0001 or better.

Because so many students either "strongly agreed" or "agreed" with these statements, the author computed their combined percentages in column 8 of the table. The values in this column average 80 percent, and many scores were substantially higher than this value. These high percentages suggest that students viewed the term project in favorable terms, and in aggregate suggest that the term project helped them better understand the items enumerated in questions 1-6 of the survey instrument.

Question 9 of the survey stated "This project helped me understand how the various components of a database fit together in a unified project," and therefore asked students to provide their global view of the project. Like questions 1-6, the results were positive.

Although it is tempting to assign numerical values to these agreement factors and take averages for individual questions, such computations would make little sense unless every student's perceptions of what the categories of "strongly agree," "agree," and so forth, were scaled identically. Because this isn't likely, the author performed an alternate chi-square test to investigate the likelihood that the distribution of answers for each question in Figure 2 was uniformly distributed. This tests the hypothesis that students were undecided about the learning value of project for each of the skill components mentioned in the survey questions. The last column of Figure 2 shows the test statistics computed for these tests, all of which were statistically significant at the .0001 level.

The one exception to the generalization that the project helped students understand the various tools of Access databases (tables, forms, queries, and so forth) was the responses to question 7. The wording of this question was "It was helpful to listen to the classroom presentations of other students before I turned in my own project." Here, students were much less positive in their responses, and seven students strongly disagreed with it (i.e., chose "5" on the survey). This was a surprising finding because of the reasons cited above (i.e., the thinking that the timing of the presentations and later due dates would help developers fine tune their applications). We suspect that a few students might have misinterpreted this question. One student strongly disagreed, for example, because he or 
she "went second for the presentations."

Questions 8 and 10 of our survey asked student opinions about some of the mechanics of the project assignment. Question 8 stated "It was helpful to have the project grading sheet before I turned in my own project." As shown in Figure 1, the aggregate results were positive and similar to the results for the first six questions. Finally, question 10 stated "I thought that the weighting for this project in determining my final grade for this course was fair." The actual project weighting was 30 percent, which was consistent across sections of the course. Again, the results were positive.

\section{Working in Groups}

Finally, the survey asked students if they preferred to work by themselves, or with one or two others in a group. Only the students in one section of the course were given the option to work in groups, so this was an interesting question for us. Figure 3 shows the distribution of answers to this question. In a nutshell, the survey showed that the majority of students who had to work alone said that they preferred to work alone, while the majority of those students who chose to work in groups said that they preferred to work in groups. These statistics are statistically significant by almost any measure.

Students were also asked to give their reasons for their preferences, but opinions varied. For example, one student from the worked-alone set of students wrote "I liked working on my own. It made me make sure to do the assignment." Another wrote "I learned more by doing it all myself." A third wrote: "...[I] have had difficulty getting together on other group projects." And finally, a fourth wrote: "Group work sucks. I'd rather rely on myself."

One reviewer of this paper suggested that students may simply be justifying their experiences. But not everyone from the work-alone classes was negative about collaborative work. One student wrote "...in the real world, it is better to work with other people." Similarly, another person from this first wave of students wrote: "I think that teamwork is a big part of life and incorporating it into this project would make it more realistic."

As noted above, most of the students in the second set preferred to work in groups. One student wrote "I loved working in groups. It was so much easier than before [and] it was nice to have someone to ask questions and feel unprepared with." Another student wrote "worked really well, having a check and double-check system, I think." A third student wrote "with two people, you can get more creative and can use each other in order to figure problems out."

Figure 3 Distribution of responses to question 13 of the survey

\begin{tabular}{|l|c|c|}
\hline & Prefer to work alone & Prefer to work in a group \\
\hline Had to work alone & 20 & 12 \\
\hline Had the option to work in a group & 2 & 11 \\
\hline
\end{tabular}

To further assess the desirability of group versus individual term project work, the author also gathered final project grades from the other instructors and then compared the average scores to average score of those students who worked in groups. Figure 4 provides the results:

Figure 4 Class mean scores for the Access project

\begin{tabular}{|l|c|c|c|c|c|}
\hline & Class \#1 & Class \#2 & Class \#3 & Class \#4 & Class \#5 \\
\hline Number of students & 12 & 14 & 19 & 20 & 29 \\
\hline Average Score & 89.4 & 85.0 & 82.4 & 83.3 & 87.2 \\
\hline
\end{tabular}


In Figure 4, "Class \#3" was the class that permitted students to work together in groups. The mean score for this class, while lower than the others, was not statistically distinguishable from the other scores. In all classes, in fact, students earned a wide range of scores, which ranged from " 0 " (for students who did not do the project) to "102" (the top score possible).

Although they are useful for examining aggregate student performance across the different sections of the course in question, the statistics in Figure 4 probably hide more than they reveal. Different instructors performed the grading, using slightly different grading formats and probably different mental benchmarks in the evaluation process. It is also noteworthy that several students in the must-work-alone classes failed to provide any term project, while all of the students in Class \#3 provided creditable term assignments. This observation suggests that group assignments may motivate students to do the work. In fairness, however, it is not known whether such nonperformers would simply have become "free riders" in group-work environments.

\section{An Alternate Measure of Project Effectiveness}

Finally, another way to evaluate the effectiveness of project assignments is to examine student opinions in end-of-semester student evaluations. Accordingly, Figure 5 provides information for the relevant questions on the author's evaluations for the fall, 2003, semester of this class.

Figure 5 fall 2003 Student Course Evaluation Scores and Departmental Means

\begin{tabular}{|l|c|c|}
\hline Evaluation statement: & $\begin{array}{c}\text { Author's class average } \\
\text { (5 point scale) }\end{array}$ & $\begin{array}{c}\text { Department } \\
\text { mean }\end{array}$ \\
\hline Made me work harder than in most other courses. & 4.0 & 4.0 \\
\hline Motivates me to do my best work. & 4.3 & 3.9 \\
\hline Gives assignments and exams that are reasonable in length and difficulty. & 4.5 & 3.9 \\
\hline Assigns grades fairly and impartially, & 4.4 & 4.2 \\
\hline Overall teaching effectiveness & 4.6 & 4.0 \\
\hline
\end{tabular}

The values in Figure 5 are ratings that indicate the extent to which students agreed with each of the evaluation statements. The survey used a five point scale, in which "1" meant "poor" and "5" was "excellent." For comparison, the table also shows departmental averages for all courses taught during the same semester.

The values for this class uniformly equaled or exceeded the departmental means, but because the standard deviations for these questions ranged from .5 to .8 , the class averages were not statistically different from the departmental values. However, these values were the highest student evaluation scores the author has ever received in this class, and among the highest teaching evaluations he had received in any other class. The extent to which those high marks are attributable to the class policies and assignments given here is unknown, but the author suspects that a positive term project experience contributed to these results.

\section{SUMMARY AND CONCLUSIONS}

It is difficult to overstate the importance of technology in the accounting curriculum in general, and the design and development of database projects in particular. There are also many advantages in using term projects to help instructors teach such concepts, including (1) the realism achieved in projects that require unstructured problem-solving skills, (2) the flexibility of student work outside the classroom, (3) the encouragement of original and creative thinking, (4) the additional learning value that students often perceive from project assignments, and (5) the benefits that often accrue from cooperative learning if students are allowed to work in teams. However, term projects take instructional resources, require subjective and time-consuming grading, and divert teaching faculty efforts from their research responsibilities.

This paper described the design and development of a comprehensive database project in an advanced 
microcomputer class that is often taken by accounting students. Key dimensions of the project included (1) an assignment/grading sheet that helps students identify required database components and helps instructors evaluate such projects efficiently, (2) a narrative report that documents the project, (3) a complete working copy of the database on disk, and (4) a short oral presentation that students give prior to the hand-in date of the project materials. The paper also provides several ideas that instructors can use to facilitate good projects, streamline the grading process, and adjust project scores in order to accomplish several ancillary objectives.

This study tested the effectiveness of these project assignments in several ways. A survey of students suggested that the term project significantly helped them better understand every component mentioned in the survey instrument, including tables, queries, forms, reports, switchboards, and macros. The author also suspects that this term project helped him achieve higher student ratings in his end-of-semester student evaluations. These findings suggest that database projects are indeed an effective way in which to teach database concepts to accounting students, and therefore should be listed among the "best practices" associated with such teaching.

Finally, a surprising finding was the lack of consensus about the desirability of working in groups. Most of the students who were allowed to work in groups expressed their preference for group work, while most of the students who were not allowed to work in groups indicated that they preferred to work alone. Each set of students had good reasons for their choices. For the reasons cited in the introductory remarks of this paper-especially the fact that most of their future professional work will likely depend upon team, rather than individual, performancethe author's preference is to continue to assign these projects on a group basis.

\section{SUGGESTIONS FOR FURTHER RESEARCH}

A host of factors can contribute to the success or failure of term projects, including the composition, disposition, educational level, social background, motivation, interest, and prior training of the students who complete such assignments as well as the competency, energy level, and dedication of the instructors who use them. The term project and subsequent analyses described here can be replicated elsewhere. Thus, one avenue for further study would be for instructors teaching similar courses to also require comprehensive database term projects (if they do not do so already), and to evaluate the effectiveness of these projects using analyses similar to those presented here.

Many permutations of the term project described above are also possible. On possibility is a project whose components are delivered piecemeal-for example, a set of database tables at "week 4" of the semester, and subsequent components delivered at similarly suitable times as students gain advanced skill sets. Another possibility is to require an entire class to work on an actual, major database project, with each student, or group of students, responsible for a well-defined subset of deliverables. Again, it is unknown to what extent such alternative approaches are more effective, less effective, or equally effective in teaching computer project skills in general, and database concepts in particular.

Finally, perhaps the most important direction to follow in future work is to develop alternate, and hopefully better, metrics by which to judge the effectiveness of database term projects. In the absence of a control group, the research presented here most measured "customer satisfaction," as gauged by survey instruments, to measure the teaching effectiveness of such term projects. But survey instruments mostly measure student perceptions, which may or may not coincide with the degree of actual learning and enhanced comprehension. In the opinion of this author, the use of (1) both experimental and control groups, and (2) comprehensive examinations would be a moreobjective evaluative standard.

The author thanks Professors Betty Cossitt and Sandy Week, both of whom helped him gather data in their sections of the subject course and reviewed an earlier draft of this manuscript, and also expresses his appreciation to two referees of the 2004 AIS-Educator's Conference, both of whom made helpful editorial suggestions for improving this paper. 


\section{BIBLIOGRAPHY AND REFERENCES}

1. American Accounting Association (AAA), "Contemporary Approaches to Teaching Accounting Information Systems" Journal of Information Systems (spring, 1987), pp. 127-156.

2. Bhattacharjee, Sudip and Lewis Shaw "Evidence that Independent Research Projects Improve Accounting Students' Technology-Related Perceptions and Skills" Accounting Education vol. 10, no. 1 (2001), pp. 83103.

3. Berry, John and Melvin A. Nyman "Small-group Assessment Methods in Mathematics" International Journal of Mathematics Education vol. 33, no. 5 (2002), pp. 641-9.

4. Bowen, Paul L., Colin B. Ferguson, Timothy H. Lehmann, and Fiona H. Rohde, "Cognitive Style Factors Affecting Database Query Performance" International Journal of Accounting Information Systems vol 3, no. 4 (December, 2003), pp. 251-74

5. Bowen, Paul L. and Fiona H. Rohde, "Further Evidence of the Effects of Normalization on End-User Query Errors: An Experimental Evaluation" International Journal of Accounting Information Systems vol. 3, no. 4 (December, 2002), pp. 255-91.

6. Bradley, Joseph A. and Ellen F. Monk "An Integration Case Using Access and Excel” in Problem-Solving Cases in Microsoft Access and Excel (Thompson Course Technology, 2003), pp. 194-204.

7. Bryant, Stephanie M. "A Blueprint for an AIS Consulting Course" Journal of Information Systems vol. 15, no. 1 (spring, 2001), pp. 19-34.

8. Burnett, Sharon "The Future of Accounting Education: A Regional Perspective" Journal of Education for Business vol. 78, no. 3 (Jan/Feb, 2003), pp. 129-35.

9. Goldsworthy, Ashley "IT Knowledge: What do Graduates Need?" Australian Accountant vol. 66, no. 9 (October, 1996), pp. 24-5.

10. Graham, Reginald A. and Beverly L. Graham, "Cooperative Learning: The Benefits of Participatory Examinations in Principles of Marketing Classes" Journal of Education for Business vol. 72, no. 3 (January/February, 1997), pp. 149-153.

11. Grauer, Robert T. and Maryann Barber "A Project for the Semester: Applying What You Have Learned" Appendix D in Exploring Microsoft Access 2002 (Upper Saddle River, New Jersey: Prentice Hall, 2002).

12. Hite, Peggy A. "An Experimental Study of the Effectiveness of Group Exams in an Individual Income Tax Class" Issues in Accounting Education vol. 11, no. 1 (spring, 1996).

13. Howieson, Bryan "Accounting Practice in the New Millennium: Is Accounting Education Ready to Meet the Challenge?" British Accounting Review vol. 35, no. 2 (June, 2003), pp. 69-104.

14. Hutchinson, Sarah E. and Glen J. Coulthard, Microsoft Access 2000 (Boston: McGraw Hill, 2000).

15. IMA, "Improving Accounting Education" Chapter 5 in IMA Studies vol. 16 (August, 2000), pp. 43-59.

16. Kalbers, Lawrence and Rebecca Rosner "An Investigation of the Emerging Trend Towards a Laptop Requirement for Accounting Majors in the USA" Accounting Education vol. 12, no. 4 (December, 2003), pp. 341-363.

17. McCarthy, William E., "The REA Modeling Approach to Teaching Accounting Information Systems" Issues in Accounting Education vol. 18, no 4 (November, 2003), pp. 427-41.

18. Marcoulides, George A. and Mark G. Simkin "Evaluating Student Papers: The Case for Peer Review" Journal of Business Education vol. 67, no. 2 (November/December, 1991), pp. 220-223.

19. Lont, David, Alan MacGregor, and Roger Willett "Technology and the Accounting Profession" Chartered Accountants Journal vol. 77, no. 1 (February, 1998), pp. 331-33.

20. Quarstein, Vernon A. and Polly A. Peterson "Assessment of Cooperative Learning: A Goal-Criterion Approach" Innovative Higher Education vol. 26, no. 1 (fall, 2001), pp. 59-77.

21. Schrage, Michael "Your Idea is Brilliant: Glad I Thought of It" Fortune vol. 142, no. 9 (October 16, 2000), pp. 412-4.

22. Van Meer, Greg, and Mike Adams "Accounting Information Systems Curriculum: An Empirical Analysis of the Views of New Zealand-based Accounting Academics and Practitioners" Accounting Education vol. 5, no. 4 (1996), pp. 283-92. 


\section{APPENDIX: SURVEY INSTRUMENT}

The IS 201 instructors are interested in learning whether the Access project that was assigned this semester helped you better understand the capabilities of Access. Do you agree or disagree with the following statements? Please circle your answer to each question. An answer of "1" means you strongly agree with a statement below, an answer of " 5 " means you strongly disagree, and so forth.

1. The project helped me understand the importance of Access tables

2. The project helped me better understand the uses of Access queries.

3. The project helped me better understand the uses of Access forms and subforms

4. The project helped me better understand the uses of Access reports.

5. The project helped me better understand the uses of switchboards.

6. The project helped me better understand the uses of macros.

7. It was helpful to listen to the classroom presentations of other students before I turned in my own project.

8. It was helpful to have the instructor's project grading sheet before I turned in my own project.

9. This project helped me understand how the various components of a database fit together in a unified project.

10. I thought that the weighting for this project in determining my final grade for this course was fair

If you disagree, what weight (as a percent) would be fair? $\%$

$\begin{array}{ccccc}\begin{array}{l}\text { Strongly } \\ \text { Agree }\end{array} & \text { Agree } & \text { Neutral } & \text { Disagree } & \begin{array}{c}\text { Strongly } \\ \text { Disagree }\end{array} \\ 1 & 2 & 3 & 4 & 5 \\ 1 & 2 & 3 & 4 & 5 \\ 1 & 2 & 3 & 4 & 5 \\ 1 & 2 & 3 & 4 & 5 \\ 1 & 2 & 3 & 4 & 5 \\ 1 & 2 & 3 & 4 & 5 \\ 1 & 2 & 3 & 4 & 5 \\ 1 & 2 & 3 & 4 & 5 \\ 1 & 2 & 3 & 4 & 5 \\ 1 & 2 & 3 & 4 & 5\end{array}$

11. Please circle your current major:

Accounting Information Systems

Other Business

Non-business (please specify here

12. How much of the material on Access covered this semester do you think an accounting major should know? Please answer as a percent of the total material covered this semester, and please answer even if you are not an accounting major: percent

13. If this Access project is assigned next semester, would you prefer to work by yourself or with one or two other students? Please circle your choice and use the space below to give reasons for your preference.

14. To improve this assignment in the future, what changes, if any, would you make? Please answer here. 